\author{
ALEKSANDRA SZYMAŃSKA \\ (iD) https://orcid.org/0000-0002-3380-5396 \\ Uniwersytet Łódzki \\ Wydział Filologiczny \\ Instytut Rusycystyki \\ Zakład Literatury i Kultury Rosyjskiej \\ 90-226 Łódź \\ ul. Pomorska 171/173 \\ aleksandra.szymanska@uni.lodz.pl
}

\title{
ДОН ЖУАН УХОДИТ В СЕТЬ. (О СПЕЦИФИКЕ МИРОВОГО ОБРАЗА В УСЛОВИЯХ ИНТЕРНЕТА) ${ }^{1}$
}

\author{
DON JUAN GOES ONLINE: \\ THE FUNCTIONING OF A WORLD-LITERATURE \\ FIGURE IN INTERNET CONDITIONS
}

\begin{abstract}
Статья представляет собой продолжение рассуждений по поводу изменений, которые претерпевает образ Дон Жуана в условиях сетевой литературы. Произведения сетевых авторов, апеллирующие к литературной классике, являются довольно распространенным явлением. Кажется, что установка на интертекстуальность является одной из писательских стратегий в интернете. Предметом нашего интереса стали произведения, отсылающие к образу Дон Жуана, опубликованные на русских литературных интернет-порталах, не включенные в процесс офф-лайн, не замеченные критиками. Основной задачей было выявление ведущих при создании образа тенденций, а также результаты, к которым привело их употребление. Рассмотрение группы текстов, принадлежащих к сетевой литературе, позволило нам сделать замечания по поводу бытования образа, рожденного в недрах испанской литературы XVII века, в специфических условиях интернета.
\end{abstract}

Ключевые слова: Дон Жуан, сетевая литература, интертекстуальность, авторские стратегии.

The article is a continuation of discussions about the changes that the literary image of Don Juan undergoes at present in online literature. Appealing to literary classics is quite common in the works of Internet authors. Intertextuality seems to be one of the writing strategies on the web. The subject of our interest are the works referring to the literary image of Don Juan published on Russian literary websites, not included in the offline process and overlooked by literary critics. The main task

${ }^{1}$ Статья выполнена при финансовой поддержке филологического факультета Лодзинского университета (Fundusz Rozwoju Wydziału Filologicznego UŁ; проект „Mit Don Juana w literaturze rosyjskiej", 2019-2020). 
has been to identify the leading tendencies in creating the image of Don Juan, as well as the results to which employing them led. Analyses of a group of texts belonging to online literature allow the author of the paper to comment on the ways in which a literary image born in the Spanish literature of the $17^{\text {th }}$ century continues to exist in the peculiar Internet conditions.

Keywords: Don Juan, online literature, intertextuality, writing strategies.

Предметом нашего интереса в статье станут размещенные на русских общедоступных литературных порталах произведения, в которых авторы обращаются к знаковому имени Дон Жуан и связанному с ним кругу тем и мотивов. Повышенный интерес к данному литературному образу на интернет-порталах послужил поводом для рассуждений о причинах его популярности в сети, а также для обобщений по поводу специфики образа в новой среде существования. Мы не претендуем на анализ сложного явления самодеятельной интернет-литературы, поскольку ее развитие - постоянный процесс in statu nascendi. Мы сосредоточимся на выявлении особенностей трактовки известного мотивно-образного комплекса литературного мифа о Дон Жуане сетевыми авторами.

В качестве объекта исследования мы выбрали произведения, опубликованные на четырех литературных порталах: Проза.ру, Стихи.ру, Поэзия.ру и Театральная библиотека Сергея Ефимова, не включенные в литературный процесс офф-лайн, не замеченные литературоведами и критиками르.

Интернет с его общедоступностью привлекает непрофессиональных авторов возможностью получить быстрый отклик на свое произведение. Однако читательский интерес, как правило, оказывается непродолжительным. Этот факт не останавливает желающих использовать интернет для самовыражения. В то же время обилие авторов в сети не гарантирует

${ }^{2}$ Пьеса Ирины Мухаметовой Дон Жуан и Дон Кихот (Проза.ру, 2010), драма Дмитрия Подчуфарова Гибель Дон Жуана (Стихи.ру, 2002), пьеса в стихах Татьяны Ширяевой Несчастный Дон Жуан (Театральная библиотека Сергея Ефимова, информация о дате публикации отсутствует), музыкальная народная комедия Николая Чапайкина и Юрия Войтова Дон-Жуан по-изарицынски (Театральная библиотека Сергея Ефимова, 2015), пьеса Галины Силиной Дон Жуан. Двадиать четьре часа (Театральная библиотека Сергея Ефимова, 2016), стихотворение Станислава Минакова Дон Хуан. Курение пейота (2003, количество посещений на 6 ноября 2019 г. - 2531), Надежды Бурановой «Мужчина с прошлым Дон Жуана...» (2006, количество посещений на 6 ноября 2019 г. - 2021), Александра Карпенко «И женщины приходят к Дон Жуану...» (2009, количество посещений на 6 ноября 2019 г. - 1550), Александра Мельника «Отдохни, дон Хуан...» (2010, количество посещений на 6 ноября 2019 г. - 1302), Иосифа Когана Дон Жуан (2010, количество посещений на 6 ноября 2019 г. - 1237), М. Галина «Когда бы Дон Жуан...» (2010, количество посещений на 6 ноября 2019 г. - 1795), Михаила Резницкого Дон Жуан из Севильи (2011, количество посещений на 6 ноября 2019 г. - 1607), Марка Луцкого Двустишия старого Дон Жуана (2017, количество посещений на 6 ноября 2019 г. - 452) - все на сайте Поэзия.ру, стихотворение Виктора Байгужакова Монолог Дон Жуана (2012) на сайте Стихи.ру. 
появление новых и оригинальных литературных тем. Распространенным явлением на литературных сетевых порталах становится эксплуатация классического наследия. Один из примеров тому - обращение к общеизвестному мировому образу Дон Жуана.

Во всех обнаруженных нами в сети произведениях, несмотря на их родовую принадлежность (драма или лирика), связь с известным литературным образом и сюжетом маркирована уже в заглавии - Гибель Дон Жуана, Несчастный Дон Жуан, Дон-Жуан по-иарииьнски, Дон Жуан. Двадиать четьре часа, Дон Жуан из Севильи, Монолог Дон Жуана, Двустишия старого Дон Жуана, «Отдохни, дон Хуан...» и др. Заглавие обещает, таким образом, присутствие знакомого героя. Прецедентное имя позволяет реципиенту узнать его, несмотря на меняющийся внешний антураж. Это, в свою очередь, пробуждает в читателе чувство удовлетворенности собственной культурной компетентностью в сфере культурных феноменов. Выбор заглавия приобретает особое значение при публикации произведения в интернете. Здесь оно выступает в роли важнейшего поискового слова, которое влияет на посещаемость сайта.

Почти во всех найденных нами произведениях сохраняются также традиционные для участников донжуанского сюжета имена, отсылающие, правда, к разным литературным традициям: Лепорелло, Сганарель, Анна, Эльвира. Авторы, помещающие героя в экзотическое для современного читателя пространство и время, заменяют его имя и титул узнаваемым вариантом или придумывают достоверные обстоятельства, которые объясняют его непривычное наименование. Так, например, Дон Жуан становится Иваном ${ }^{3}$ (Г. Силина, Дон Жуан. Двадиать четыре часа) или гангстером по кличке Дон Жуан (Т. Ширяева, Несчастный Дон Жуан).

Главный герой во всех найденных нами произведениях создается с опорой на доминантные черты Дон Жуана, но в разных текстах они проявляются с разной интенсивностью. Герои, соотносимые с Дон Жуаном, изображаются уверенными в себя любимцами женщин, противниками брака, изгнанниками, неустрашимыми грандами, поэтами; их именуют развратниками, совратителями и безбожниками, врагами инквизиции, проклятыми людьми, убийцами. В некоторых произведениях подчеркивается лицемерие Дон Жуана, в других, напротив, герой - враг и обличитель лицемерия. Достаточно устойчивым является мотив его усталости и старости, а также мотив пьянства.

Немногие из доступных нам произведений сохраняют традиционные пространственно-временные координаты истории о Дон Жуане. Их авторы

\footnotetext{
${ }^{3}$ Как известно, имя Иван является русским вариантом имени Жуан - в переводе с испанского (Хуан) на французский, а затем на русский.
} 
не слишком заботятся о воспроизведении испанского колорита, используя лишь некоторые его атрибуты: серенады, монархический строй, деятельность инквизиции, испанские имена или названия городов. Ряд авторов помещает героя в другое, нетрадиционное пространство либо в настоящее время, делая его более узнаваемым и близким современному русскому читателю.

Сетевые авторы, пишущие о Дон Жуане, стремятся сохранить установку на жизнеподобие. Это проявляется, в частности, в интерпретации образа Командора и связанного с ним мотива загробной мести. Достоверность образа достигается за счет наделения его чертами, а точнее, пороками, не чуждыми современному человеку, знакомыми либо по собственному опыту, либо благодаря телевидению или публикациям прессы. Например, Командор превращается в наглого пьяницу, который ругается грубыми словами и издевается над своей женой (Т. Ширяева, Несчастный Дон Жуан), или в женщину - вдову военного, неуравновешенную феминистку, которая ненавидит мужчин и заступается за честь своей единственной дочери (Г. Силина, Дон Жуан. Двадиать четыре часа). Стремление к рационализации фантастических элементов проявляется и иным образом - фантастическая история о чудесном оживлении статуи оказывается хитрой интрижкой братьев инквизиторов (Н. Чапайкин и Ю. Войтов, Дон-Жуан по-изарицынски). В некоторых произведениях Командор только упоминается в связи с прошлым Дон Жуана, но он не оказывает никакого влияния на дальнейшую судьбу соблазнителя (Д. Подчуфаров, Гибель Дон Жуана).

Предложенные сетевыми авторами сюжетные решения обусловлены мировоззренческими переменами. Они свидетельствуют об устройстве жизни на основе рациональных норм, что отражается в подходе к таким понятиям как «преходящее» и «вечное», а также в погоне за все новыми ощущениями. Отход от важной, если не самой важной, составляющей донжуанского сюжета ведет к серьезным последствиям - чаще всего к его упрощению или даже к тривиализации.

Ряд рассматриваемых нами произведений заканчивается либо подготовкой к свадьбе, либо венчанием Дон Жуана. Именно, такой финал оказывается самым распространенным. Вместо развязки с появлением карающей статуи, авторы выводят героя на новый жизненный путь, который противоречит идее Дон Жуана. Брак для него равнозначен завершению скитаний, отдыху от прежней - бурной жизни. Героя к этому шагу, чаще всего, приводит мысль о приближающейся старости и связанных с ней недугах.

Помимо Дон Жуана и Командора, некоторые изменения претерпевает также образ слуги, выполняющего в большинстве анализируемых произведений функцию хитрого шута и комедианта. В одном случае слугой Дон Жуана становится переодетая влюбленная женщина, которая заставляет 
его вступить с нею в брак. Стоит отметить возрастающую роль слуги для развития сюжета, а также приобретенный им за долгие годы скитаний с Дон Жуаном опыт в отношениях с женщинами.

Интересными изменениями сопровождается образ Анны. Перенос известных мировых героев в современную Россию с ее проблемами и острыми социальными вопросами (эмиграция, феминизм, СПИД, насилие в семье, отсутствие равенства полов, алкоголизм, депрессия и др.) отразился на женских образах. Анна из испанской матроны превращается то в жертву мужа-пьяницы, которая сравнивается с алмазом на том основании, что она не гуляющая, не пьющая и не курящая, то в библиотекаршу-скромницу - одну из последних в городе непорочных и невинных девушек.

Апелляция сетевых авторов к общеизвестному образу связана с явлением интертекстуальности. Стоит, однако, отметить, что игра с текстами классической литературы в большинстве случаев не требует от читателя глубоких литературных знаний. Она основана на тиражируемости узнаваемых словесных формул, ситуаций и мотивов, представленных в новом антураже. Обнаружение литературного источника чаще всего не привносит в текст произведения новых смыслов. Оно может доставить читателю удовольствие оттого, что он замечает сходство с классическими произведениями русской литературы, такими как: Маскарад Лермонтова, Стихи о Прекрасной Даме Блока или стихотворение «Умом Россию не понять...» Тютчева. Обращение к хрестоматийным текстам ограничено, в основном, использованием легко узнаваемых мотивов - мести, ревности, скуки, обмана, яда, рока, клеветы, злодейства, страха и образов - ревнивого, опытного мужа, верной, молодой жены, танцующих масок.

Иным примером установки на интертекстуальность является введение в текст фрагментов произведений донжуанского круга, либо воспроизведение в новой обстановке хорошо известных диалогов. Отметим, что цитация здесь не выполняет смыслообразующей функции, а лишь создает иллюзию включенности произведения в литературную традицию. Подобный эффект достигается авторами за счет иронического перефразирования классических (но не только) цитат: «Нельзя же первым встречным доверяться, / В России мудрено не растеряться. / Ее аршином общим не измеришь - / Не сломишь, не раздавишь, не похеришь!» $\left.{ }^{4}\right)$.

В большинстве произведений обнаруживается тенденция к снижению и дискредитации понятий или фигур из сферы sacrum. Так, ангелы становятся проститутками, монах - гомосексуалистом, поэт - пьяницей, Дон

${ }^{4}$ Т. Ширяева, Несчастный Дон Жуан, [электронный ресурс] http://www.theatre-library. $\mathrm{ru} /$ authors/sh/shiryaeva [9.12.2019]. 
Кихот - постаревшим несостоявшимся героем. В произведении Ирины Мухаметовой Дон Жуан и Дон Кихот встреча Дон Жуана с Дон Кихотом оборачивается эффектом обманутого ожидания. Вместо столкновения двух жизненных установок читатель становится свидетелем фарсовой ситуации, в которой Дон Жуан и Дон Кихот оказываются жертвами хитрых женщин, заставляющих их вступить в брак.

Отдельную часть рассматриваемых произведений составляют стихотворения, среди которых мы выделили две основные группы. В первую из них вошли стихотворения, авторы которых стремились дать «серьезную» интерпретацию образа, насыщая свои тексты раздумьями экзистенциального характера.

Медиативной настроенности героя способствует психоделическое, галлюциногенное состояние, возникшее в результате курения пейота. Оно оказывается видом убежища либо от скудной действительности, в которой Дон Жуан остался одиноким, лишенным жизненной цели, разочарованным («Одиноко? Уныло ли? Голо?...»), либо от всеохватывающего страха («Страх вползает в меня ниоткуда. / Очарованный желтизной, / я сегодня шаманить не буду. / Что-то станется нынче со мной» ${ }^{6}$ ). К подобным размышлениям о познавательных возможностях человека, о мимолетности жизни, неизбежности смерти, болезни души приводит героя осознание безысходности своего положения.

Вторую группу составляют стихотворения, иронически освещающие известный образ. Значительным является «обыгрывание» авторами темы старости и потери сексуальных сил Дон Жуаном. Герой, теряя свои жизненные силы, не в состоянии осчастливить всех нуждающихся женщин ( «Уходит невостребованной дама. / Звучат шаги - и плачет Дон Жуан» ${ }^{7}$ ), из соблазнителя он превращается в импотента («В его глазах - боязнь инфаркта, / Тахикардия ... Весь букет. / К тому же новый страх - фальстарта... / Он - Дон Жуан? Теперь уж - нет» ${ }^{8}$. С годами он становится склеротиком, теряет память («Имел я даму? Вот вопрос! / Не помню, хоть убей! Склероз!» $)^{9}$. Сомнению подвергается на только слава Дон Жуана-соблазнителя,

${ }^{5}$ С. Минаков, Дон Хуан. Курение пейота, [электронный ресурс] https://poezia.ru/ works/19893 [10.12.2019].

${ }^{6}$ A. Мельник, «Отдохни, дон Хуан...», [электронный ресурс] https://poezia.ru/ works/81765 [10.12.2019].

${ }^{7}$ А. Карпенко, «И женщины приходят к Дон Жуану...», [электронный ресурс] https:// poezia.ru/works/71380 [10.12.2019].

${ }^{8}$ Н. Буранова, «Мужчина с прошлым Дон Жуана...», [электронный ресурс] https:// poezia.ru/works/43658 [10.12.2019].

${ }^{9}$ М. Луцкий, Двустишия старого Дон Жуана, [электронный pecypc] https://poezia.ru/ works/126527 [10.12.2019]. 
но и Дон Жуана-поэта («И пусть тебе удался добрый хит, / Но ты всего лишь сочинитель песен... / Когда бы Дон Жуан писал стихи, / Он был бы никому не интересен!» $\left.{ }^{10}\right)$. Ироническая интерпретация образа приводит к грустному заключению: от прежних подвигов Дон Жуана осталась лишь слава соблазнителя («И унесся прах по ветру, / Не осталось ничего, / Лишь восславили поэты / Хобби грешное его» ${ }^{11}$ ).

Как в драматических, так и в поэтических опытах сетевых авторов не была упущена возможность обратиться к литературной классике. Пожалуй, самым ярким примером являются аллюзии на стихотворение Блока Шаги Командора, которое послужило автору точкой отсчета при разработке образа. Узнаваемыми в тексте становятся: образ Командора, олицетворяющего время, атмосфера тишины, вызванной смертью Донны Анны, лунный и туманный пейзаж:

\footnotetext{
Что ты знаешь о жизни моей, человек?

Что ты знаешь о жизни вообще?

Ты послушай шаги - это топает Век

Командором в испанском плаще.

«Донна Анна!» - кричу, а в ответ тишина,

Словно я в этом мире один.

Только дыней на небе желтеет Луна -

Я не видел прекрасней картин ${ }^{12}$.
}

В обоих случаях - в драматических и лирических интерпретациях - наблюдается тенденция к дегероизации Дон Жуана. Слабость характера сетевые авторы компенсируют динамикой действия, обилием невероятных происшествий, неожиданным освещением героя. Однако ориентация на вкусы сетевого читателя, который привык к погоне за новыми ощущениями, неожиданными поворотами действия, шокирующими превращениями героев, варианты развития сюжета, предлагаемые сетевыми авторами, не гарантируют приращения смысла. Наоборот, большинство текстов отличается редукцией смыслов. В такой ситуации известный мировой образ вместо того, чтобы стать объектом креативной рецепции, ведущей к рождению оригинального высказывания художника о своей

\footnotetext{
${ }^{10}$ М. Галин, «Когда бы Дон Жуан...», [электронный ресурс] https://poezia.ru/works/82539 [10.12.2019].

${ }^{11}$ М. Резницкий, Дон Жуан из Севильи, [электронный pecypc] https://poezia.ru/ works/90515 [10.12.2019].

${ }^{12}$ В. Байгужаков, Монолог Дон Жуана, [электронный ресурс] https://www.stihi. $\mathrm{ru} / 2012 / 02 / 01 / 11098$ [10.12.2019].
} 
реальности, превращается в легко узнаваемый стереотип. Стереотип, в свою очередь, гарантирует читателю чувство безопасности, позволяет получить удовлетворение от погружения в описываемые перипетии, тем самым отвечая потребности уйти от повседневной жизни, а главное - потребности в развлечении. Таким образом, успех текста основан не на его оригинальности, а напротив, на узнаваемости и повторяемости.

Эффект узнаваемости обеспечивается также актуализацией классики. Сетевые авторы сознательно используют приемы интертекстуальности и литературной игры. Одна из принципиальных черт сетературы - ее вторичность, когда литературный процесс не генерирует новое содержание, а воспроизводит известное. Итак, отличительными чертами поэтики исследуемых произведений являются перекодирование и игра с текстами классической литературы, актуализация стереотипов, а также тиражирование формул и приемов.

\section{References}

Bayguzhakov, Viktor. Monolog Don Zhuana. https://www.stihi.ru/2012/02/01/11098

Buranova, Nadezhda. Muzhchina s proshlym Don Zhuana... https://poezia.ru/works/43658

Galin, M. Kogda by Don Zhuan... https://poezia.ru/works/82539

Karpenko, Aleksandr. I zhenshchiny prikhodyat k Don Zhuanu... https://poezia.ru/works/71380

Lutskii, Mark. Dvustishiya Don Zhuana. https://poezia.ru/works/126527

Melnik, Aleksandr. Otdokhni, don Khuan... https://poezia.ru/works/81765

Minakov, Stanislav. Don Khuan. Kurenie peiota. https://poezia.ru/works/19893

Reznitskii, Mikhail. Don Zhuan iz Sevili. https://poezia.ru/works/90515

Shiryaeva, Tatyana. Neschastnyi Don Zhuan. http://www.theatre-library.ru/authors/sh/shiryaeva 